NIST Technical Note 1916

\title{
Methods for characterizing a radiation detector for specifying radiation fields during testing against standards for homeland security applications
}

\author{
A. L. Sallaska \\ L. Pibida \\ B. Minniti \\ C. M. O’Brien
}

This publication is available free of charge from: http://dx.doi.org/10.6028/NIST.TN.1916 
NIST Technical Note 1916

\title{
Methods for characterizing a radiation detector for specifying radiation fields during testing against standards for homeland security applications
}

\author{
A. L. Sallaska \\ L. Pibida \\ B. Minniti \\ C. M. O'Brien \\ Radiation Physics Division \\ Physical Measurement Laboratory
}

This publication is available free of charge from: http://dx.doi.org/10.6028/NIST.TN.1916

April 2016

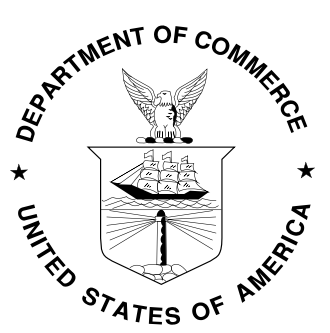

U.S. Department of Commerce Penny Pritzker, Secretary 
Certain commercial entities, equipment, or materials may be identified in this document in order to describe an experimental procedure or concept adequately. Such identification is not intended to imply recommendation or endorsement by the National Institute of Standards and Technology, nor is it intended to imply that the entities, materials, or equipment are necessarily the best available for the purpose.

National Institute of Standards and Technology Technical Note 1916

Natl. Inst. Stand. Technol. Tech. Note 1916, 14 pages (April 2016) CODEN: NTNOEF

This publication is available free of charge from: http://dx.doi.org/10.6028/NIST.TN.1916 


\title{
Methods for characterizing a radiation detector for specifying radiation fields during testing against standards for homeland security applications
}

\author{
A. L. Sallaska, L. Pibida†, R. Minniti, and M. O'Brien \\ National Institute of Standards and Technology, Gaithersburg, MD 20899
}

\begin{abstract}
A wide variability exists among commercial radiation detection instruments used to measure exposure rate or ambient dose equivalent rate. These instruments are used to measure both the radiation background and the radiation field produced by radioactive sources that are used to test other types of radiation detection systems against different consensus document standards. Most radiation fields specified in the ANSI standard are quite low, ranging from $0.05 \mu \mathrm{Sv} / \mathrm{h}$ to $0.5 \mu \mathrm{Sv} / \mathrm{h}$ above background. Due to the radiation fields being so low in intensity, the uncertainty of the measurements made with these instruments can be potentially quite large. As a result of these large uncertainties, it is possible that the response of the various parameters being tested by the standards (e.g., alarm indication, radionuclide identification) will be dependent on the specific radiation detector employed by the testing laboratory. In this work, we used two different methods to set the radiation fields to analyze the differences that can be expected. One method is based on measurements performed with a high pressure ion chamber while the second method is based on calculating the radiation fields from a known source activity using a point source estimate. The sources of uncertainties in both methods are identified and are reflected in the differences that can be expected in setting the radiation fields. In order to achieve consistency across different testing laboratories in setting radiation fields, we provide insight to what are the most relevant factors that affect the determination of the field using either one of the two methods.
\end{abstract}

Keywords: radiation detection for homeland security, ANSI N42 standards, testing of radiation detection equipment

† Corresponding author: leticia.pibida@nist.gov 


\section{Introduction}

In order to safeguard the country against trafficking of illicit nuclear and radiological material, both national and international documentary standards have been developed to ensure the adequate performance of commercially available radiation detection instruments. Testing of radiation detection instruments against standards should provide realistic expectations of the devices' capabilities to governments and first responders. Currently, the American National Standards Institute/Institute of Electrical and Electronics Engineers (ANSI/IEEE) and the International Electrotechnical Commission (IEC) each have eight published standards for homeland security applications encompassing a myriad of detection equipment types [1 - 16]. Although some measurement systems identify radionuclides, all systems measure the magnitude of the radiation field in some form (e.g., $\mu R / h, \mu S v / h$, counts/s, unitless) ${ }^{1}$.

In order to test different types of radiation detection systems, some standards specify the values to be used for the exposure rate or ambient dose equivalent rate (instead of the source activity) in order to provide the laboratories with the flexibility to use their current sources at a distance that provides the required field strength. Therefore, independent knowledge of the radiation field and its associated uncertainty is paramount. If the radiation field from the background or a radiation source is not measured accurately, an instrument under test may pass the standard requirements in one laboratory and fail in another. Clearly, this is unacceptable, and a robust method for measuring the various intensities of the radiation fields is needed.

As discussed in Ref [17], it has been difficult to reach a consensus among the different standards working groups on how to specify and measure these radiation fields. In regard to the latter, there is also no consensus as to the quantity to be measured, generally given as exposure rate (in units of $\mu R / h$ ) or ambient dose equivalent rate (in units of $\mu \mathrm{Sv} / \mathrm{h}$ ). The work presented in Ref. [17] explored the variability of determining the radiation field with three commercially available radiation monitors and compared the rates to theoretical calculations. The data indicated that the choice of equipment has a significant impact on the measured values, as the spread in results for the respective trials typically ranged from $10 \%$ to $50 \%$. To expand the data from Ref. [17], an additional radiation monitor, the model GE RSS-131ER, was used to perform measurements with identical test configurations and radiation sources as previously done. Supplementary trials at multiple distances (and, hence, radiation fields) and heights were also examined.

\section{Measurements}

The exposure rate produced by the radiation field was measured using a high pressure ion chamber (HPIC) model GE RSS-131ER ${ }^{2}$. Encased in a $31 \mathrm{~cm} \times 31 \mathrm{~cm} \times 36 \mathrm{~cm}$ aluminum enclosure, this unit

\footnotetext{
${ }^{1}$ NIST does not endorse the use of non-SI units. This paper uses non-SI units because it addresses the requirements listed in the ANSI/IEEE published standards.

${ }^{2}$ Certain commercial equipment, instruments, or materials are identified in this paper to foster understanding. Such identification does not imply recommendation or endorsement by the National Institute of Standards and Technology, nor does it imply that the materials or equipment identified are necessarily the best available for the purpose.
} 
contains $2533 \mathrm{kPa}$ (25 atmospheres) of argon in a $25.4 \mathrm{~cm}$-diameter stainless steel sphere (wall thickness of $3.2 \mathrm{~mm}$ ) and has the capability to measure exposure rates from background levels up to $100 \mathrm{R} / \mathrm{h}$. This radiation monitor has the ability to operate independently (not connected to a PC) in a range of different surroundings, and data files (consisting of time stamped exposure rate or count rate data) produced by the HPIC may be later downloaded to a computer after the measurements are completed. The acquired data may also be observed in real time if the HPIC is connected to an external computer. The software used to download the data from the HPIC to the PC is version 6.1. In addition to monitoring exposure rate, the instrument has the ability to generate environmental information such as wind-speed and ambient temperature. From the response curve given in the manual, the detector's cutoff energy is approximately $50 \mathrm{keV}$, where the response is $\approx 10 \%$ of its relatively constant value between $300 \mathrm{keV}$ and $10 \mathrm{MeV}$.

Three different sets of radiation exposure rate measurements were made:

1) with the HPIC centered at a distance of $1 \mathrm{~m}$ from the source (the distance tested in Ref. [17]),

2) with the HPIC centered at distances from the source that were calculated to produce fields of $5 \mu R / h$, $10 \mu \mathrm{R} / \mathrm{h}$, and $50 \mu \mathrm{R} / \mathrm{h}$, and

3) with the HPIC at offsets up to $6.4 \mathrm{~cm}$ from center of the HPIC to test the monitor's sensitivity to offset.

Ten independent exposure rate measurements were recorded for each data set. Tests at a source-todetector distance of $1 \mathrm{~m}$ were acquired with three different integration times: $10 \mathrm{~s}, 60 \mathrm{~s}$, and $300 \mathrm{~s}$. All other tests were conducted with the $60 \mathrm{~s}$ integration time only. Reported uncertainties are expanded for a coverage factor of $k=2$, unless otherwise noted.

Exposure rate measurements were acquired in a low-scatter room with sources mounted in a polymethyl methacrylate (PMMA) holder. The holder was placed on a precision track that allows repositioning the source within $0.1 \mathrm{~mm}$, and there is no additional source shielding from the holder. The instrument was positioned on a laboratory jack approximately $60 \mathrm{~cm}$ above the track so the height could be adjusted and aligned with the source center. The radionuclides utilized for these tests are listed in Table 1. Sources are encapsulated in $0.25 \mathrm{~mm}$ thick stainless steel, the fabrication is described in Refs. [18] and [19].

Table 1: Source activities at the time of the radiation field measurements. The relative standard uncertainty of each activity is $5 \%$. Data were taken over the course of 19 days, during which these values varied by less than $0.5 \%$ due to the long half-life of the isotopes.

\begin{tabular}{|c|c|}
\hline Radionuclide & Activity (kBq) \\
\hline${ }^{241} \mathrm{Am}$ & 1882 \\
\hline${ }^{133} \mathrm{Ba}$ & 3019 \\
\hline${ }^{60} \mathrm{Co}$ & 1119 \\
\hline${ }^{137} \mathrm{Cs}$ & 2556 \\
\hline${ }^{226} \mathrm{Ra}$ & 294 \\
\hline${ }^{232} \mathrm{Th}$ & 550 \\
\hline${ }^{232} \mathrm{U}$ & 463 \\
\hline
\end{tabular}


The energy response of the instrument is not entirely constant, and therefore all measured exposure rate data needs to be corrected for the detector's energy response. The instrument manual provides correction factors, relative to ${ }^{226} \mathrm{Ra}$, as follows: 0.507 for ${ }^{241} \mathrm{Am}, 0.980$ for ${ }^{60} \mathrm{Co}$, and 1.002 for ${ }^{137} \mathrm{Cs}$. It should be noted, however, that the manual (revision R, March 2014) incorrectly describes how to apply these factors (by multiplying the reading, rather than dividing). Using these data and other data given in the manual, values of 1.235 for ${ }^{133} \mathrm{Ba}, 1.032$ for ${ }^{232} \mathrm{Th}$, and 1.014 for ${ }^{232} \mathrm{U}$ were obtained from a fit of a sixth degree polynomial, shown in Fig. 1 as a function of gamma-ray energy. These values were obtained from the weighted response for all the gamma-ray energies (with energies greater than $50 \mathrm{keV}$ ). It should be noted that the ${ }^{232} \mathrm{Th}$ source exhibits some self-attenuation at energies less than $\approx 390 \mathrm{keV}$. This effect was measured with a high-purity germanium detector and used as an additional weighting factor in calculating the average energy, lowering its value by $12 \%$. This increased the correction factor for this source by less than $2 \%$.

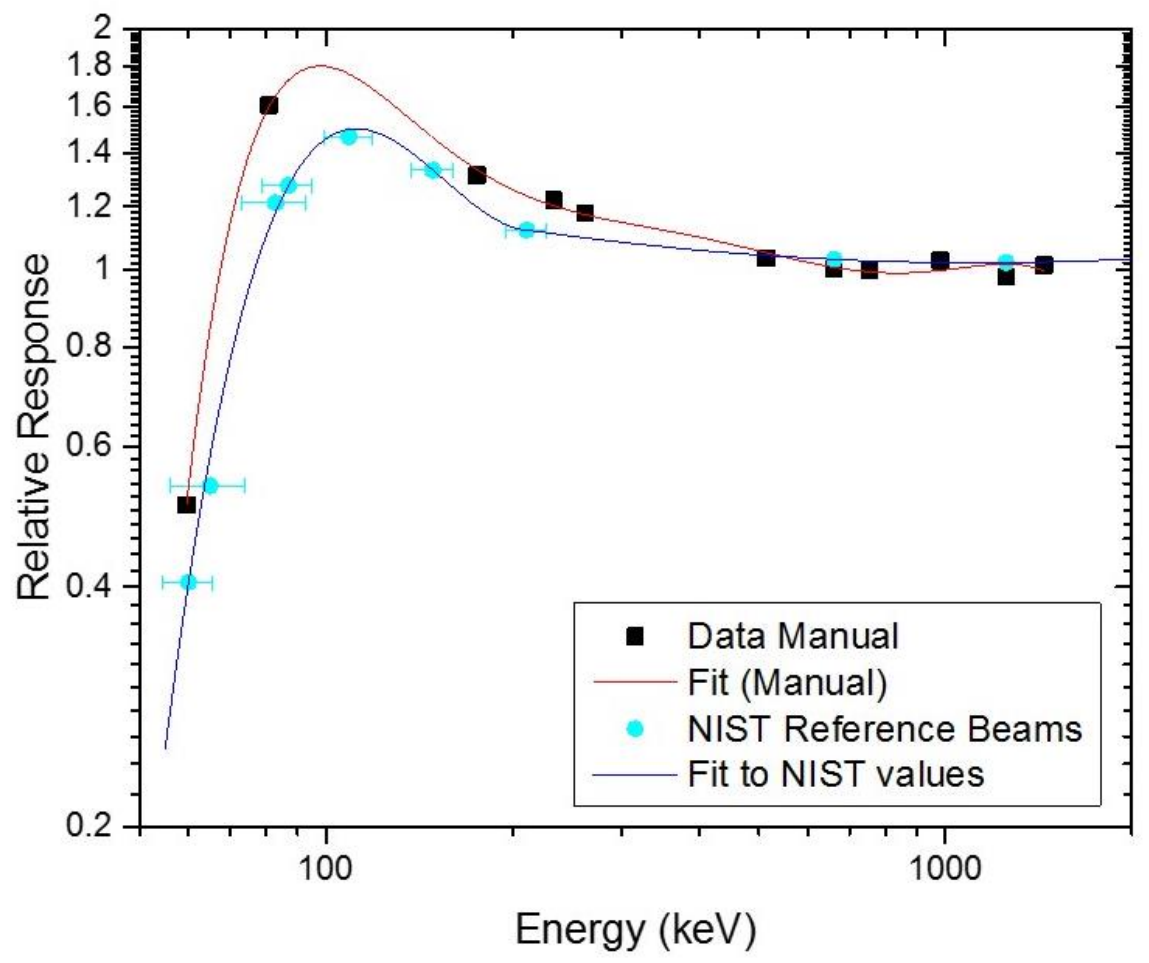

Figure 1: Detector relative response obtained from data reported in the instrument manual and from measurements made in the NIST reference radiation beam. The detector response data from the manual, which does not include any uncertainties, are relative to ${ }^{226} \mathrm{Ra}$. The fit to the data from the instrument manual and the NIST measurements are also shown.

The accuracy of the correction factors provided in the manual were compared against seven reference beams at the National Institute of Standards and Technology (NIST), using ${ }^{137} \mathrm{Cs},{ }^{60} \mathrm{Co}$, and $\mathrm{x}$-rays at different exposure rates. For most beam quality and calibration rates, multiple sets of 10 readings were recorded, as well as their respective means and standard deviations. The weighted average of these values was calculated and its uncertainty was combined with the uncertainty in the beam calibration at 
the specified rate. Then for each beam energy, the mean and standard deviation among the various rates was determined using the weighted average at each rate. These values are also shown in Fig. 1.

The ${ }^{137} \mathrm{Cs}$ beams produced exposure rates of $0.286 \mathrm{mR} / \mathrm{h}, 7.146 \mathrm{mR} / \mathrm{h}, 42.85 \mathrm{mR} / \mathrm{h}$, and $127.4 \mathrm{mR} / \mathrm{h}$ with associated relative expanded uncertainties of $1 \%(k=2)$ and for source-to-detector (center) distances of $300 \mathrm{~cm}$. For a fixed exposure rate, the difference in the mean values between sets of 10 readings was less than $0.5 \%$. The instrument readings were higher than the reference values by $2.6 \%$ (at 0.286 $\mathrm{mR} / \mathrm{h}$ ), $4.3 \%$ (at $7.146 \mathrm{mR} / \mathrm{h}$ ) and $2.5 \%$ (at $127.4 \mathrm{mR} / \mathrm{h}$ ) and $1.9 \%$ (at $42.85 \mathrm{mR} / \mathrm{h}$ ).

For the ${ }^{60} \mathrm{Co}$ beam, fields of $42.85 \mathrm{mR} / \mathrm{h}$ and $102.2 \mathrm{mR} / \mathrm{h}$ (also with uncertainties of $1 \%(k=2)$ ) were generated with the same beam by moving the detector to positions at $300 \mathrm{~cm}$ and $195 \mathrm{~cm}$, respectively. Reproducibility among sets of 10 readings was less than $0.1 \%$. For this source, the instrument readings were higher than the reference value by $2.3 \%$ (at $102.2 \mathrm{mR} / \mathrm{h}$ ) and $1.9 \%$ (at $42.85 \mathrm{mR} / \mathrm{h}$ ). For the relative instrument response curve, an average energy of $1252.993 \mathrm{keV}$ (weighted by the emission probabilities of the two gamma-ray lines) was used to display the instrument response to ${ }^{60} \mathrm{Co}$. Weighted averages were used to combine data for one radionuclide at different exposure rates.

Calibration measurements were also performed with $\mathrm{x}$-ray beams, yielding average energies of $60 \mathrm{keV}$ (LK70 at $141 \mathrm{mR} / \mathrm{h}$ and $271 \mathrm{mR} / \mathrm{h}$ ), $65 \mathrm{keV}$ (NS80 at $719 \mathrm{mR} / \mathrm{h}$ ), $83 \mathrm{keV}$ (NS100 at $424 \mathrm{mR} / \mathrm{h}$ ), $87 \mathrm{keV}$ (LK100 at $181 \mathrm{mR} / \mathrm{h}$ and $357 \mathrm{mR} / \mathrm{h}$ ), $109 \mathrm{keV}$ (LK125 at $255 \mathrm{mR} / \mathrm{h}$ ), $149 \mathrm{keV}$ (LK170 at $216 \mathrm{mR} / \mathrm{h}$ ), and $211 \mathrm{keV}$ (LK240 at $424 \mathrm{mR} / \mathrm{h}$ ) [20, 21]. The energy spread in the $\mathrm{x}$-ray beams ranged from $18 \%$ to $32 \%$ from the effective energy, and the uncertainties in the calibrated rates spanned from $1.1 \%$ to $2.2 \%$ ( $k=$ 2). No strong exposure rate dependence was observed. For the beams at $60 \mathrm{keV}$ and $87 \mathrm{keV}$, due to constraints in the experimental setup, the calibrated exposure rate was measured relative to the front face of the detector. These values were corrected using the inverse square law for the dependence of the exposure rate with the source-to-detector distance to estimate the value at the center of the detector. Measurements both at the front face and center of the detector were performed on a separate $x$-ray range to investigate the potential deviations from the inverse square law. The maximum observed difference due to scaling one of these rates and comparing to its respective measured value was $1.6 \%$, and most differences were much smaller. Although for the higher energies, the values from the instrument manual agrees to within a few percent of the NIST instrument response calibration, the values at low energies are somewhat larger, ranging from $7 \%$ to $24 \%$ larger than the NIST calibration values at the respective energies.

The instrument relative response, obtained from the NIST reference beam measurements (see Figure 1), was fitted using two polynomials. A $3^{\text {rd }}$ degree polynomial was used to fit the values between $60 \mathrm{keV}$ and $211 \mathrm{keV}$ and $2^{\text {nd }}$ degree polynomial was used to fit the values between $211 \mathrm{keV}$ and $1.253 \mathrm{MeV}$. The relative response for the ${ }^{133} \mathrm{Ba},{ }^{226} \mathrm{Ra},{ }^{232} \mathrm{Th}$ and ${ }^{232} \mathrm{U}$ sources were calculated using these fitting curves. The values of 1.0732 for ${ }^{133} \mathrm{Ba}, 1.0267$ for ${ }^{226} \mathrm{Ra}, 1.0646$ for ${ }^{232} \mathrm{Th}$ and 1.0629 for ${ }^{232} \mathrm{U}$ were obtained from the weighted response of the all gamma-ray energies emitted by each source for energies greater than $40 \mathrm{keV}$.

All exposure rates measured for the different sources using the instrument were corrected for energy response either using the efficiencies measured directly with the NIST beams for the ${ }^{241} \mathrm{Am},{ }^{137} \mathrm{Cs}$ and ${ }^{60} \mathrm{Co}$ sources or from a fit of the NIST calibration points shown in Figure 1 for the other radionuclides (i.e., ${ }^{133} \mathrm{Ba},{ }^{226} \mathrm{Ra},{ }^{232} \mathrm{Th},{ }^{232} \mathrm{U}$ ). 


\section{Results}

Results for the measurements using the ionization chamber with sources placed at a distance of $1 \mathrm{~m}$, sources producing fields of $5 \mu \mathrm{R} / \mathrm{h}, 10 \mu \mathrm{R} / \mathrm{h}$, and $50 \mu \mathrm{R} / \mathrm{h}$, and with sources at various offset heights are discussed. Data are also compared to the theoretical calculations listed in Ref. [17].

Theoretical calculations are shown for each measurement (except for height offset tests). Details regarding the theory using both a point source approximation and Monte Carlo transport codes are reported in Ref. [17]. For measurements at a source-to-detector distance of $1 \mathrm{~m}$, point-source calculations are given for a $40 \mathrm{keV}$ cutoff energy. For the instrument, all rates have been corrected for photon energy response using efficiencies measured directly from the NIST reference beams (see Fig. 1) or from interpolating these values.

\subsection{Source measurements at a distance of $1 \mathrm{~m}$}

Each source listed in Table 1 was placed at a distance of $1 \mathrm{~m}$ from the center of the ionization chamber. Exposure rates measured at this distance are shown in Table 2 for integration times of $10 \mathrm{~s}, 60 \mathrm{~s}$, and $300 \mathrm{~s}$, along with the point-source method calculations from Ref. [17]. The standard deviation of the instrument measurements are obtained from 10 measurements. Subtracted backgrounds for the instrument were typically on the order of $(6.6 \pm 0.2) \mu R / h$. Differences in calculated rate values between previous [17] and current data sets arise from source decay due to the 18 month time lapse between measurements.

Table 2: Summary of exposure rate measurements made with the HPIC model instrument placed at a distance of $1 \mathrm{~m}$ from the source. Rates (in $\mu \mathrm{R} / \mathrm{h}$ ) are shown for various integration times, $T_{\text {int }}$, along with their respective standard deviation ( $S$, expressed in \%). Rates are background subtracted and corrected by the detector energy response factor as a function of photon energy (see Section 2 and Figure 1). Calculated exposure rates using the point-source method are given with a $40 \mathrm{keV}$ cutoff energy, $v_{c}$.

\begin{tabular}{|c|c|c|c|c|c|c|c|}
\hline \multirow{2}{*}{ Source } & \multicolumn{6}{|c|}{ Measurements of Exposure Rate $(\boldsymbol{\mu R} / \mathrm{h})$ for $\mathbf{3}$ Integration Times } & \multirow{2}{*}{ Calculations } \\
& $\mathrm{T}_{\text {int }}=10 \mathrm{~s}$ & $\% \mathrm{~S}$ & $\mathrm{~T}_{\text {int }}=60 \mathrm{~s}$ & $\% \mathrm{~S}$ & $\mathrm{~T}_{\text {int }}=300 \mathrm{~s}$ & $\% \mathrm{~S}$ & $v_{c}=40 \mathrm{keV}$ \\
\hline${ }^{241} \mathrm{Am}$ & $0.715 \pm 0.919$ & 129 & $0.370 \pm 0.625$ & 169 & $0.518 \pm 0.665$ & 128 & 0.625 \\
\hline${ }^{133} \mathrm{Ba}$ & $19.8 \pm 0.3$ & 1.7 & $19.9 \pm 0.4$ & 2.1 & $19.9 \pm 0.2$ & 0.8 & 15.6 \\
\hline${ }^{60} \mathrm{Co}$ & $42.1 \pm 0.3$ & 0.8 & $41.9 \pm 0.3$ & 0.7 & $41.5 \pm 0.2$ & 0.5 & 38.8 \\
\hline${ }^{137} \mathrm{Cs}$ & $25.6 \pm 0.5$ & 1.9 & $25.9 \pm 0.5$ & 1.9 & $25.7 \pm 0.2$ & 0.8 & 24.0 \\
\hline${ }^{226} \mathrm{Ra}$ & $7.42 \pm 0.18$ & 2.4 & $8.1 \pm 0.9$ & 10.7 & $7.5 \pm 0.2$ & 2.0 & 6.10 \\
\hline${ }^{232} \mathrm{Th}$ & $16.0 \pm 0.4$ & 2.4 & $16.0 \pm 0.3$ & 2.0 & $16.0 \pm 0.3$ & 1.6 & 16.9 \\
\hline${ }^{232} \mathrm{U}$ & $9.7 \pm 0.2$ & 2.4 & $9.7 \pm 0.3$ & 2.7 & $9.6 \pm 0.1$ & 1.4 & 8.47 \\
\hline
\end{tabular}

Aside from the ${ }^{241} \mathrm{Am}$ source (its count rate was close to the background level, due to the detector's rapid decline in efficiency for low-energy gamma rays), the standard deviation for the instrument readings was less than $3 \%$ even with the $10 \mathrm{~s}$ integration time and decreased to $0.5 \%$ to $2 \%$ with the $300 \mathrm{~s}$ integration time.

Figure 2 shows the measured exposure rates, corrected and uncorrected by the relative energy response, relative to the rates calculated with the point source method for a $300 \mathrm{~s}$ integration time for all instruments. As illustrated in the figure, the measured exposure rates for the GE detector are mostly 
within or near the $\pm 15 \%$ boundaries, with no disagreement larger than $32 \%$. Although only the $300 \mathrm{~s}$ integration results are shown, the values for the shorter integration times do not show appreciable differences aside from slightly increased uncertainties (see values in Table 2). The quality of this agreement for the point source method is similar when the measured data is compared to the more involved Monte Carlo N-Particle Transport Code (MCNPX) calculation (see Ref. [17]). Data for ${ }^{241} \mathrm{Am}$ is not shown in Figure 2 because the uncertainties are quite large due to the weakly observed signal and are off scale. The ratio compared to calculation is $0.83 \pm 1.06$ when the readings were corrected by the instrument energy response and $0.34 \pm 0.43$ when the readings were not corrected by the instrument energy response.

Lastly, data observed on the computer screen during testing was compared to data written to corresponding event files of the instrument. Although differences were observed, the magnitude of the differences was not greater than $1 \%$. It is possible this is a software issue.

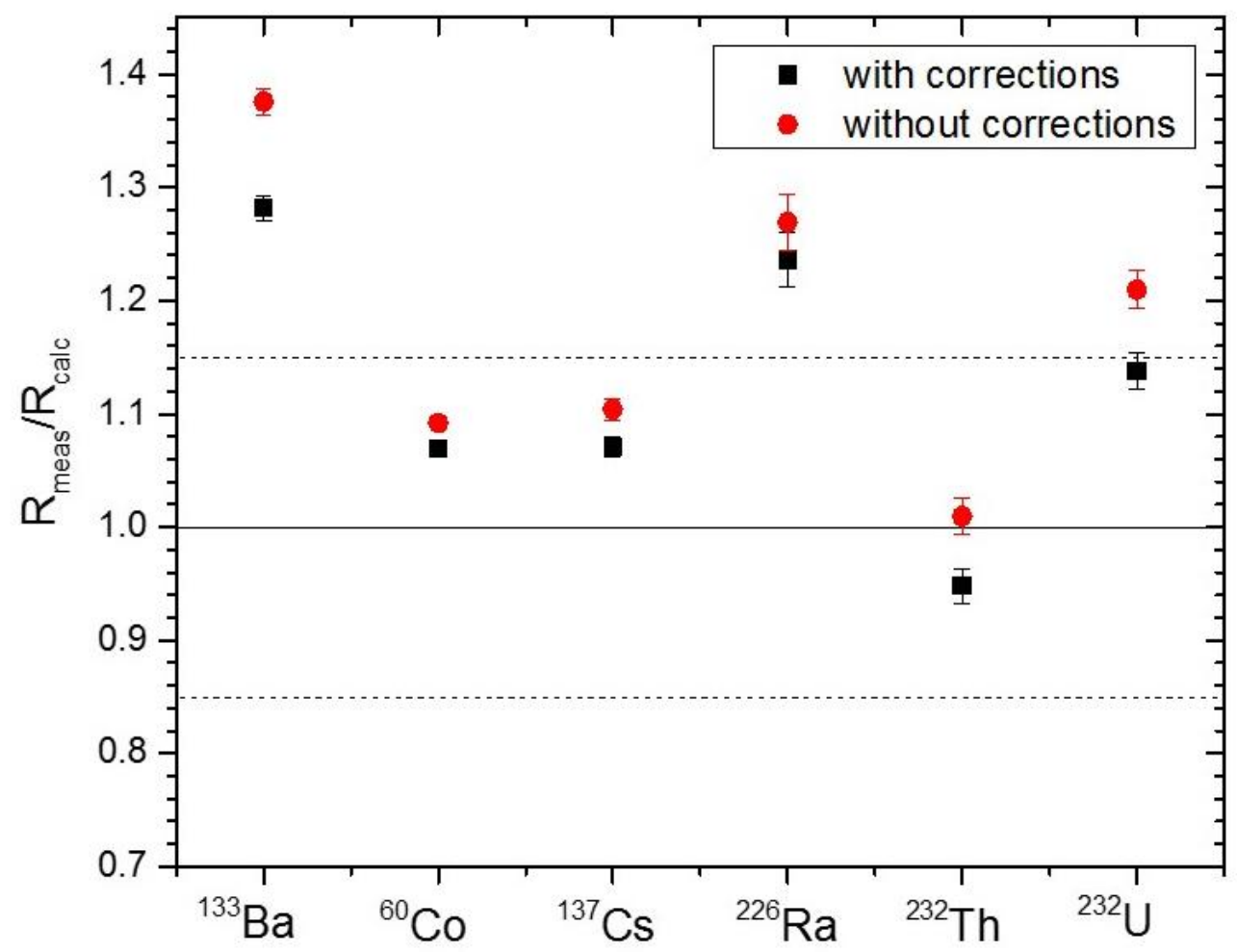

Figure 2: Comparison of measured exposure rates $\left(R_{\text {meas }}\right)$ to their respective calculated rates $\left(R_{\text {calc }}\right)$ at a distance of $1 \mathrm{~m}$ for $300 \mathrm{~s}$ integration times corrected and uncorrected by the instrument response as a function of energy. Uncertainties are statistical only, and dotted lines give the $\pm 15 \%$ boundaries. Though agreement is good, the ${ }^{241} \mathrm{Am}$ source uncertainty is off scale for the instrument and not shown $(0.95 \pm 2.44)$. 


\subsection{Fields of $5 \mu \mathrm{R} / \mathrm{h}, 10 \mu \mathrm{R} / \mathrm{h}, 50 \mu \mathrm{R} / \mathrm{h}$}

In addition to measuring the radiation field produce by the radioactive sources at a distance of $1 \mathrm{~m}$, measurements were also performed at distances that were calculated to produce radiation fields of $5 \mu \mathrm{R} / \mathrm{h}, 10 \mu \mathrm{R} / \mathrm{h}$, and $50 \mu \mathrm{R} / \mathrm{h}$ (see Table 3). Point sources were used for the measurements; therefore, the measurements were compared with point-source method calculations.

The exposure rate measurements are summarized in Table 3, and their comparison to calculations is shown in Figure 3. Similar to results for the $1 \mathrm{~m}$-distance, these values were also background subtracted and corrected for non-linear energy response. Correction factors due to detector response are discussed in Section 2. Ten trials were performed, and the mean and standard deviation derived from those trials is shown. Uncertainties have been expanded with a coverage factor of $k=2$ for direct comparison with measurements at $1 \mathrm{~m}$. Only a $60 \mathrm{~s}$ integration time was used. Due to the length of the track, a field of $5 \mu \mathrm{R} / \mathrm{h}$ was unable to be achieved for the ${ }^{60} \mathrm{Co}$ source. It was also not possible to position the ${ }^{241} \mathrm{Am}$ source close enough to set up a $50 \mu \mathrm{R} / \mathrm{h}$ field due to the size of the detector. Ratios of $0.81 \pm$ 0.76 and $0.74 \pm 0.16$ for the $5 \mu \mathrm{R} / \mathrm{h}$ and $10 \mu \mathrm{R} / \mathrm{h}$ fields, respectively, for the ${ }^{241} \mathrm{Am}$ source are not plotted in Figure 3.

A similar response across radionuclides is observed as with the data with varying fields at a fixed distance of $1 \mathrm{~m}$. Within a single radionuclide, comparisons to calculation yield consistent results at each nominal field value of $5 \mu \mathrm{R} / \mathrm{h}, 10 \mu \mathrm{R} / \mathrm{h}$, and $50 \mu \mathrm{R} / \mathrm{h}$.

Table 3: Summary of measurements with the instrument at distances calculated to yield $5 \mu \mathrm{R} / \mathrm{h}$, $10 \mu \mathrm{R} / \mathrm{h}$, and $50 \mu \mathrm{R} / \mathrm{h}$ fields, along with their respective standard deviation (S, expressed in \%). Rates are background subtracted and corrected for energy response. Measurements with dashes were unable to be performed (see text).

\begin{tabular}{|c|c|c|c|c|c|c|c|c|c|}
\hline \multirow{2}{*}{ Source } & \multicolumn{3}{|c|}{$\mathbf{5} \boldsymbol{\mu R} / \mathbf{h}$} & \multicolumn{3}{|c|}{$\mathbf{1 0} \boldsymbol{\mu R} / \mathbf{h}$} & \multicolumn{3}{|c|}{$\mathbf{5 0} \boldsymbol{\mu R} / \mathbf{h}$} \\
\cline { 2 - 10 } & $\begin{array}{c}\text { Distance } \\
(\mathrm{m})\end{array}$ & $\begin{array}{c}\text { Rate } \\
(\mu \mathrm{R} / \mathrm{h})\end{array}$ & $\% S$ & $\begin{array}{c}\text { Distance } \\
(\mathrm{m})\end{array}$ & $\begin{array}{c}\text { Rate } \\
(\mu \mathrm{R} / \mathrm{h})\end{array}$ & $\% S$ & $\begin{array}{c}\text { Distance } \\
(\mathrm{m})\end{array}$ & $\begin{array}{c}\text { Rate } \\
(\mu \mathrm{R} / \mathrm{h})\end{array}$ & $\% S$ \\
\hline${ }^{241} \mathrm{Am}$ & 0.354 & $4.04 \pm 1.90$ & 47 & 0.251 & $7.44 \pm 0.79$ & 10.6 & 0.112 & - & - \\
\hline${ }^{133} \mathrm{Ba}$ & 1.757 & $6.50 \pm 0.30$ & 4.7 & 1.242 & $12.9 \pm 0.3$ & 2.6 & 0.555 & $65.0 \pm 0.3$ & 0.5 \\
\hline${ }^{60} \mathrm{Co}$ & 2.776 & - & - & 1.963 & $10.9 \pm 0.3$ & 2.7 & 0.878 & $53.9 \pm 0.4$ & 0.8 \\
\hline${ }^{137} \mathrm{Cs}$ & 2.190 & $5.48 \pm 0.32$ & 5.9 & 1.548 & $10.8 \pm 0.3$ & 2.5 & 0.692 & $54.1 \pm 0.4$ & 0.7 \\
\hline${ }^{226} \mathrm{Ra}$ & 1.114 & $6.40 \pm 0.27$ & 4.2 & 0.788 & $12.4 \pm 0.4$ & 3.4 & 0.352 & $64.3 \pm 0.4$ & 0.6 \\
\hline${ }^{232} \mathrm{Th}$ & 1.819 & $5.08 \pm 0.30$ & 5.9 & 1.286 & $9.8 \pm 0.4$ & 3.6 & 0.575 & $49.5 \pm 0.5$ & 1.0 \\
\hline${ }^{232} \mathrm{U}$ & 1.295 & $5.89 \pm 0.27$ & 4.6 & 0.916 & $11.6 \pm 0.4$ & 3.8 & 0.410 & $59.2 \pm 0.5$ & 0.9 \\
\hline
\end{tabular}




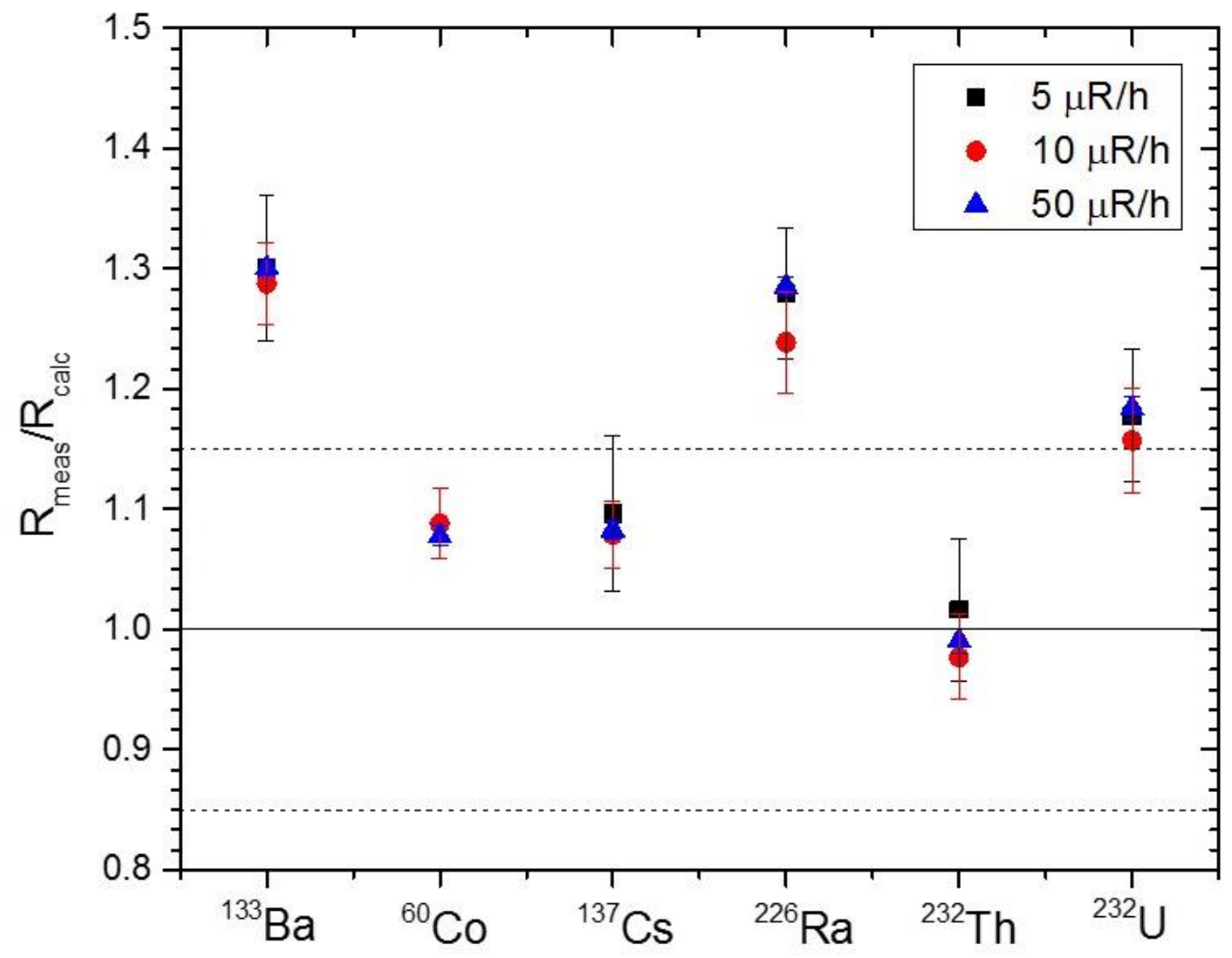

Figure 3: Comparison of measured exposure rates $\left(R_{\text {meas }}\right)$ to their respective calculated rates $\left(R_{\text {calc }}\right)$ for fields of $5 \mu \mathrm{R} / \mathrm{h}, 10 \mu \mathrm{R} / \mathrm{h}$, and $50 \mu \mathrm{R} / \mathrm{h}$. Uncertainties are statistical only, and dotted lines give the $\pm 15 \%$ boundaries. Measurements were not possible with a $5 \mu \mathrm{R} / \mathrm{h}$ field for the ${ }^{60} \mathrm{Co}$ source (see text). The ${ }^{241} \mathrm{Am}$ source data is not shown because uncertainties are off scale (see text for values).

\subsection{Testing sensitivity to source offset}

Because of the fairly large size of the instrument compared to the other instruments (a 25.4-cm diameter sphere pressurized with argon encased in a $31 \mathrm{~cm} \times 31 \mathrm{~cm} \times 36 \mathrm{~cm}$ aluminum box), a third set of measurements was performed in order to assess the effect of source offset. Three height offsets were measured at two extreme distances-a close distance $(0.25 \mathrm{~m})$ and a far distance $(2.089 \mathrm{~m}$, at the end of the track) - with a ${ }^{60} \mathrm{Co}$ source (see Table 1) using a 60 s integration time. Data was background subtracted (background $\approx(6.7 \pm 0.2) \mu \mathrm{R} / \mathrm{h}$ ) and corrected based on the energy response dependence. 
Table 4: Summary of measurements with the instrument for ${ }^{60} \mathrm{Co}$ source at different offsets from the detector center. Rates are in $\mu \mathrm{R} / \mathrm{h}$. Uncertainties are only statistical for the far distance and include systematics for the close distance (see text).

\begin{tabular}{|c|c|c|}
\hline Offset $(\mathbf{c m})$ & Rate $\left(\boldsymbol{d}_{\text {close }}\right)$ & Rate $\left(\boldsymbol{d}_{\text {far }}\right)$ \\
\hline-6.35 & $685.9 \pm 20.6$ & - \\
\hline-3.18 & $732.1 \pm 28.2$ & - \\
\hline-1.59 & $740.8 \pm 20.9$ & - \\
\hline 0 & $747.9 \pm 10.4$ & $9.7 \pm 0.5$ \\
\hline 1.59 & $755.4 \pm 3.0$ & $9.8 \pm 0.5$ \\
\hline 3.18 & $739.4 \pm 11.9$ & $9.8 \pm 0.7$ \\
\hline 6.05 & $700.3 \pm 8.3$ & $9.8 \pm 0.6$ \\
\hline
\end{tabular}

Results are shown in Table 4 and Figure 4. Baseline measurements were recorded on the centerline of the detector sphere at each distance, and height offsets were chosen as fractions of the radius (approximately $1 / 8,1 / 4$, and $1 / 2$ ). The inner spherical anode and outer spherical cathode have radii of $2.54 \mathrm{~cm}$ and $12.7 \mathrm{~cm}$, respectively. Because the source height was fixed, the detector was raised (positive heights in the table and figure) and lowered (negative heights) with the use of a laboratory jack. The maximum height of $6.05 \mathrm{~cm}$ was slightly less than $1 / 2$ the detector radius of $6.35 \mathrm{~cm}$ because of the finite range of the jack.

A mean rate and standard deviation were calculated from 10 readings at each height. These rates were difficult to reproduce at the close distance after repositioning the instrument at the same height due to the size and the weight of the instrument. Statistical uncertainties on each separate set of 10 measurements at this distance were less than $0.2 \%$. In order to quantify the observed differences in the multiple sets of data at a fixed height, a mean of three separate sets of 10 trials was calculated, and the uncertainties in the table and figure indicate the standard deviation among those three sets. It should be noted that, for the maximum height of $6.05 \mathrm{~cm}$, only two data sets of data were taken, and multiple passes at the same height to check reproducibility were performed only at the close distance, these were used to determine the systematic uncertainty. Because the instrument readings were less sensitive to height offset at the far distance, 10 trials were logged at each height only once and only for positive detector offsets.

For the far distance, the exposure rate is not sensitive to height offset within at least half the radius of the detector, as one would expect due to the small change in illuminated solid angle. Uncertainties for this case are purely statistical. The solid angle effect is much more pronounced at the close distance (roughly one radius length away from the edge of the sphere). Due to the systematic uncertainties in the data due to repositioning, it is unclear if the effect can be observed within $3.5 \mathrm{~cm}$ of the instrument center. The solid angle effect is becomes unequivocally apparent at the largest offset, where the rate falls by nearly $10 \%$.

The effect of source offset was also tested at the NIST calibration range with beams delivering ${ }^{137} \mathrm{Cs}$ radiation fields of $0.286 \mu \mathrm{R} / \mathrm{h}$ and $7.146 \mu \mathrm{R} / \mathrm{h}$ at a distance of $300 \mathrm{~cm}$. The offset ranged from $-6.35 \mathrm{~cm}$ to $6.35 \mathrm{~cm}$, relative to the detector center. For this extended beam, as opposed to the point sources discussed above, no sensitivity to offset was observed for either field strength, as expected due to the large beam size. 

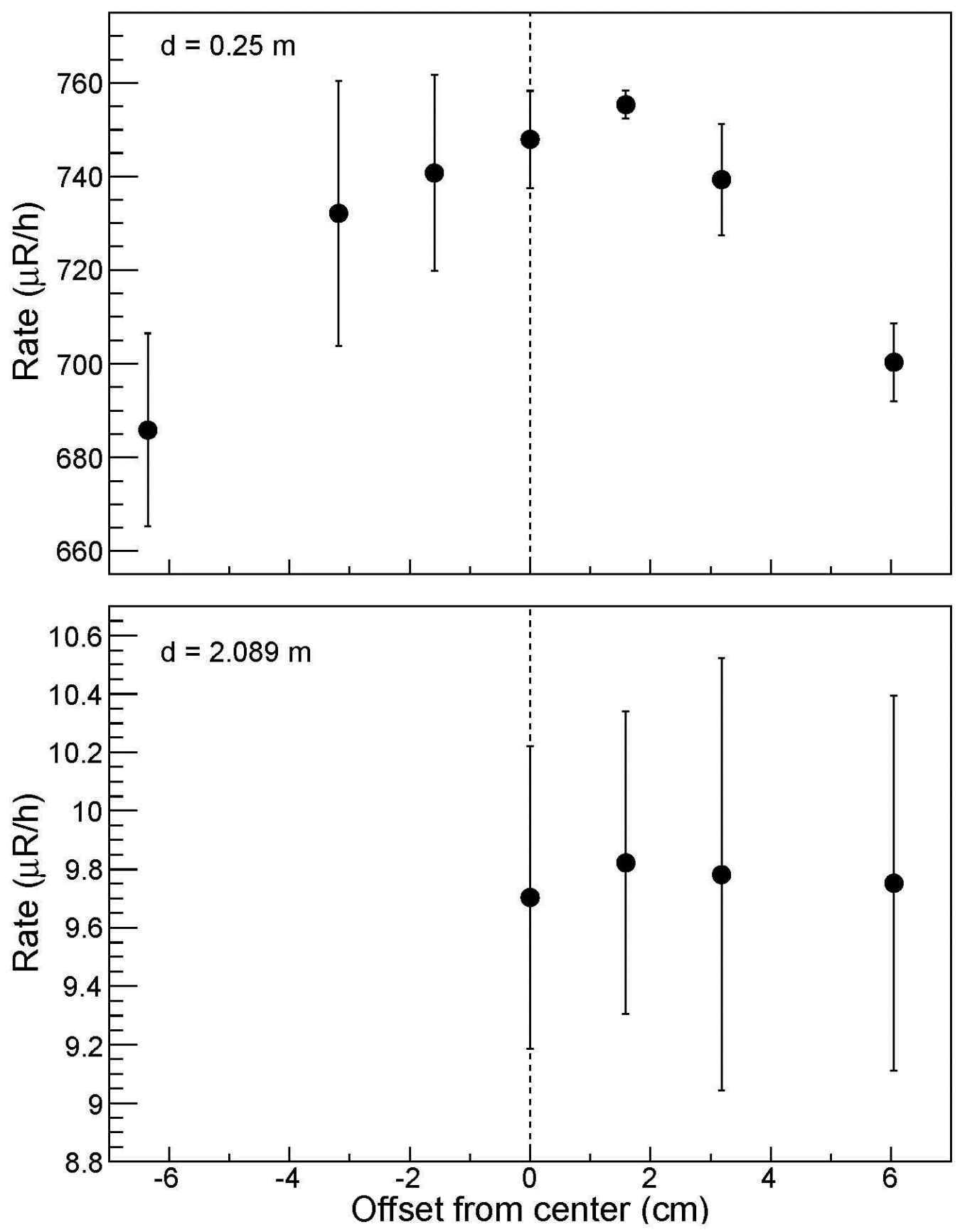

Figure 4: Comparison of exposure rates for ${ }^{60} \mathrm{Co}$ source offset at a close distance $(d=0.25 \mathrm{~m})$ and a far distance $(d=2.089 \mathrm{~m})$. Uncertainties are only statistical for the far distance and include the systematic uncertainty obtained from the standard deviation due to the repositioning of the instrument for the close distance (see text). 


\subsection{Backgrounds}

Background rates were monitored in three locations: 1) a low-scatter room (enclosed by aluminum walls and flooring) where all data with sources from Table 1 were recorded, 2) a highly shielded underground laboratory (built with low-level materials) where the instrument was exposed to high-intensity ${ }^{137} \mathrm{Cs}$ calibration beams, and 3) a first-floor office. Figure 6 shows the backgrounds in these locations over a period of 25 days.

The background rate in the low-scatter room over the course of the first seven days shown in Figure 6 was $(6.63 \pm 0.22) \mu \mathrm{R} / \mathrm{h}(3.3 \%)$ (mean and standard deviation). Several increases in exposure rate up to $40 \mu \mathrm{R} / \mathrm{h}$ to $70 \mu \mathrm{R} / \mathrm{h}$ were observed (denoted by the asterisks in the figure). It is possible that these are from sources from another group brought into the room, or they could be from cosmic rays or other background fluctuations. Small gaps in the data indicate where data from source measurements for the present tests were removed. During testing, heavy rainfall occurred multiple times and changes in the background of the instrument can be also seen in Figure 5 .

The average background in the highly shielded underground laboratory was (3.95 \pm 0.14$) \mu \mathrm{R} / \mathrm{h}(3.6 \%)$ and $(5.32 \pm 0.16) \mu \mathrm{R} / \mathrm{h}(3.1 \%)$ in the office around day 12 . The latter value in the office is nearly identical for the background for day 21 to 25 , even when including the several data points that fluctuated by up to $50 \%$.

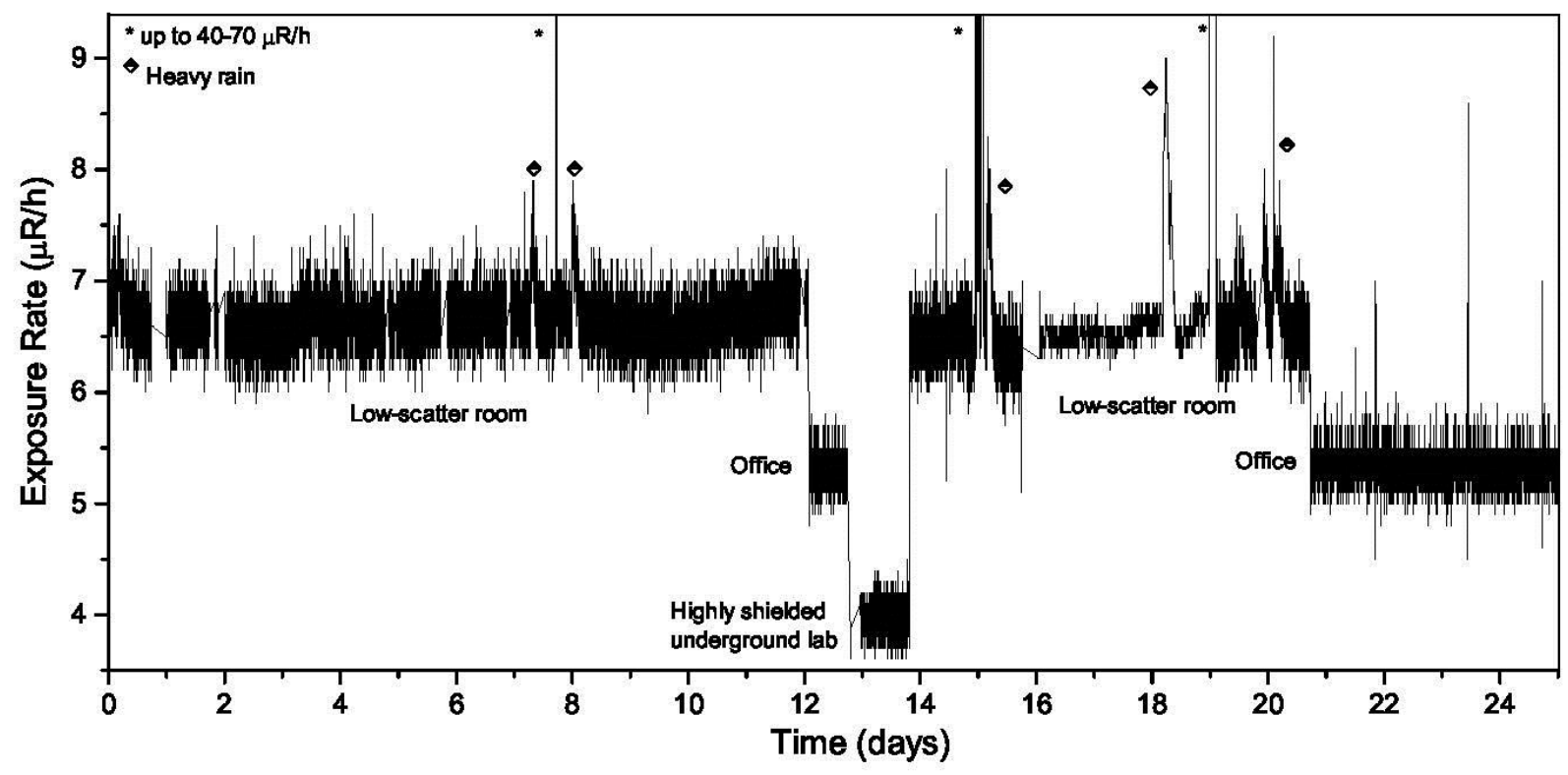

Figure 5: Background exposure rate as a function of time in three locations.

\section{Conclusions}

In this work we compared the results of determining a radiation field using two different methods. One method consisted of performing measurements with an ionization chamber while the other method 
consisted of calculation of the field based on a known activity of the radioactive sources [17], using the point-source method to calculate the exposure rate. For both methods, the radiation field was determined at a variety of source distances, heights, and radiation fields in order to assess the ability to precisely and accurately determine exposure rates. Measurements with NIST reference beams indicate the instrument response correction factors listed in the manual are accurate to within a few percent for high energies but display larger deviations up to $35 \%$ for lower energies.

Even with only a $10 \mathrm{~s}$ integration time, the precision in the instrument's readings is less than $3 \%$, and this continues to improve for longer integration times $0.5 \%$ to $2 \%$. Source offset effects were observed but only at very close source-to-detector distances. The agreement of the GE detector readings, after applying the instrument response correction factors obtained from the NIST measurements, as compared to the calculated values for the radiation fields are mostly within or near the $\pm 15 \%$ boundaries, with no disagreement larger than $32 \%$.

Background measurements were examined in three separate locations. Localized background measurements are quite stable and can be used as a solid measure for background subtraction, though care should be taken during times of heavy rainfall, depending on the location and type of building where measurements are performed.

It is our recommendation that ANSI/IEEE and the IEC consider the degree of specificity required in setting up radiation fields. The quality of the test results, when testing against written consensus standards, are dependent on quality and precision of the radiation field and background measurements for each test. If the instrumentation used to verify these fields is not consistent, the results of such tests could show a large variability depending on how the measurements are performed. Exposure rates measurements should be used only if the instrument to measure the rates has a small variability in its determination of rate, a known energy response for relative corrections, a known rate dependence, and

a known angular dependence. Another possible solution that will reduce the uncertainty in the radiation field determination would be to encourage the use of source activities or emission rates, with known source encapsulation and uncertainties and perform the test at a specific source-to-detector distance.

\section{Acknowledgments}

The authors would like to thank the Department of Homeland Security (DHS) Domestic Nuclear Detection Office (DNDO) for funding this work.

\section{References}

[1] ANSI/IEEE N42.32. “American National Standard Performance Criteria for Alarming Personal Radiation Detectors Used for Homeland Security."

[2] IEC-62401. "Radiation Protection instrumentation - Alarming personal radiation devices for detection of illicit trafficking of radioactive material."

[3] ANSI/IEEE N42.48. “American National Standard Performance Criteria for Alarming Spectroscopic Personal Radiation Detectors for Homeland Security." 
[4] IEC 62618. "Radiation Protection instrumentation - Alarming spectroscopic personal radiation devices (SPRD) for detection of illicit trafficking of radioactive material."

[5] ANSI N42.33. “American National Standard Data for Portable Radiation Detection Instrumentation for Homeland Security."

[6] IEC 62533. "Radiation Protection Instrumentation - Highly Sensitive Hand-held Instruments for Photon Detection of Radioactive Material."

[7] IEC 62534 "Radiation protection instrumentation - Highly sensitive hand-held instruments for neutron detection of radioactive material."

[8] ANSI/IEEE N42.34, “American National Standard Performance Criteria for Hand-Held Instruments for the Detection and Identification of Radionuclides."

[9] IEC-62327, “'Radiation protection instrumentation - Hand-held instruments for the detection and identification of radionuclides and for the indication of ambient dose equivalent rate from photon radiation."

[10] ANSI/IEEE N42.53, “American National Standard Performance Criteria for Backpack Based Radiation Detection Systems used for Homeland Security."

[11] IEC 62694, "Radiation protection instrumentation - Backpack-type radiation detector (BRD) for detection of illicit trafficking of radioactive material."

[12] ANSI/IEEE N42.43, “American National Standard Performance Criteria for Mobile and Transportable Radiation Monitors used for Homeland Security. "

[13] ANSI/IEEE N42.35. “American National Standard for Evaluation and Performance of Radiation Detection Portal Monitors for Use in Homeland Security."

[14] IEC 62244, “'Radiation protection instrumentation - Installed radiation monitors for the detection of radioactive and special nuclear materials at national borders."

[15] ANSI/IEEE N42.38, “American National Standard Performance Criteria for Spectroscopy-Based Portal Monitors Used for Homeland Security."

[16] IEC-62484, "Radiation protection instrumentation - Spectroscopy-based portal monitors used for the detection and identification of illicit trafficking of radioactive material."

[17] L. Pibida, M. Mille, and B. Norman. J. Res. Natl. Inst. Stand. Technol., 118:292-300, 2013.

[18] L. Lucas, L. Pibida, M. Unterweger, and L. Karam. Radiat. Protection Dosimetry, 113:108-111, 2005.

[19] L. Pibida, M. Unterweger, and L. Karam. Appl. Radiat. Isotopes, 64:1271-1272, 2006.

[20] P. Lamperti and M. O’Brien. NIST Special Publications, 250-58, 2001.

[21] ISO/IS 4037-1X and gamma reference radiations for calibrating dosimeters and dose rate meters and for determining their responses as a function of photon energy--Part 1.: Radiation characteristics and production methods. 